www.jmscr.igmpublication.org

Index Copernicus Value: 79.54

ISSN (e)-2347-176x ISSN (p) 2455-0450

crossrefDOI: https://dx.doi.org/10.18535/jmscr/v7i3.14

Journal Of Medical Science And Clinical Research

IGM Publication

An Official Publication of IGM Publication

\title{
Atlanto - Occipital Synostosis - A Detailed Study In South Indian Population
}

\author{
Authors \\ Dr K. Parthiban ${ }^{1}$, Dr M. Latha ${ }^{2 *}$, Dr K. Vidulatha ${ }^{3}$, Dr Vinovictor Jesudas ${ }^{4}$ \\ ${ }^{1}$ Associate Professor, Institute of Anatomy, Madurai Medical College, Madurai \\ ${ }^{2}$ Assistant Professor, Institute of Anatomy, Madurai Medical College, Madurai \\ ${ }^{3}$ Assistant Professor, Institute of Anatomy, Madurai Medical College Madurai \\ ${ }^{4}$ Director and Professor, Institute of Anatomy, Madurai Medical College Madurai \\ *Corresponding Author \\ Dr M. Latha
}

Assistant Professor, Institute of Anatomy, Madurai Medical College, Madurai. Tamil Nadu, India Conduct No: 9791774792, Email: latharaja1175@gmail.com

\begin{abstract}
Background: Atlanto - occipital synostosis is a congenital condition in which the atlas the first cervical vertebra is partially or completely fused with the occipital bone. The condition is also known by other names such as occipitalisation of atlas. Occipito - cervical synostosis, Atlanto-occipital fusion to name a few. The terminology assimilation of atlas, refers to the complete fusion of the first cervical vertebra to the occipital bone. It is a rare congenital anomaly with the incidence ranging from $0.14-0.75 \%$. The predilection of the condition is equal for both the sexes. The condition is of clinical importance because of the compression of the neurovascular structure found along the upper margin of the atlas vertebra thus producing neurovascular deficits which usually produces symptom during the second decade of life. Iatrogenic atlanto- occipital fusion has been tried as a mode of treatment for the management of atlantooccipital osteoarthritis. Hence, the present study aims to throw light on the importance of the incidence, symptomatology, clinical features and embryological basis of the condition.

Materials and Methods: Three hundred and fifty skulls were examined in the Institute of Anatomy, Madurai Medical College, Madurai. Out of which 3 skulls showed partial occipitalisation of atlas. The various dimensions were measured using digital vernier caliper.

Results: Three skulls showed partial occipitalisation of atlas, thus showing an incidence of $0.85 \%$

Conclusion: Occipito- cervical fusion has a varied presentation ranging from asymptomatic features, neurovascular deficits to sudden death. Hence the knowledge of the condition is important in the treatment of patients.

Keywords: Atlanto - occipital synostosis, atlanloaxial joint, osteoarthritis, sclerotome, neurovascular deficit, cervical myelopathy.
\end{abstract}

\section{Introduction}

The position of the atlas is crucial as it acts as a bridge between the globe and the neck, thus transmitting the weight of the skull to the neck. It thus got rightly named after the greek Titan holding the weight of the globe on his shoulders. 
The ring shaped atlas vertebra is atypical as it is devoid of a spine and the body. It possess a long posterior arch and a small anterior arch and two lateral masses. The lateral mass bears a superior and inferior articular facet on its respective surfaces. A tubercule is found projecting from the medial aspect of the lateral mass

A vertebral groove, is a wide groove present on the superior surface of the posterior arch of atlas. It lodges the vertebral artery along with the vertebral vein and the plexus of sympathetic nerves around it. The $\mathrm{C} 1$ spinal nerve is found deep to the artery. In this region the nerve divide in the anterior and posterior ramus. ${ }^{[9]}$

The atlanto-occipital joint is a synovial joint of condylar variety, where the concave superior articular facet of the atlas articulates with the reniform (or) hourglass shaped occipital condyles $^{[10]}$. The stability of the joint is maintained by the capsule and anterior and posterior atlanto -occipital membrane ${ }^{[11]}$. The movements possible in this joint are flexion and extension which allows for the nodding movement of the skull and a slight degree of lateral flexion.

Occipitalisation of atlas is a congenital anamoly of the cranio-vertebral system, where the atlas vertebra is either completely or partially fused with the occipital bone. Occipitalisation of atlas can be either unilateral or bilateral, complete or partial, symptomatic or asymptomatic. The synostosis is usually associated with hypoplasia of the basiocciput. The synostosis represents the most cephalad blocked vertebra, to be encountered in craniovertebral anomalies ${ }^{[2,8]}$.

\section{Materials and Methods}

About 350 adult dry human skulls of Indian origin were examined in the institute of anatomy, Madurai Medical college, Madurai. The study was conducted over a period of 2 years from 2015-2017. The skull bones were examined for occipitalisation of atlas. Sex of the skulls were not known. Various parameters were noted and measurements were taken using digital vernier caliper with an accuracy corrected to $0.01 \mathrm{~mm}$. The measurements were made by two observers to prevent inter and intra observer variations. Damaged skulls childrens skulls appearing to be affected by bone disease or skulls grossly damaged due to trauma were excluded from the study.

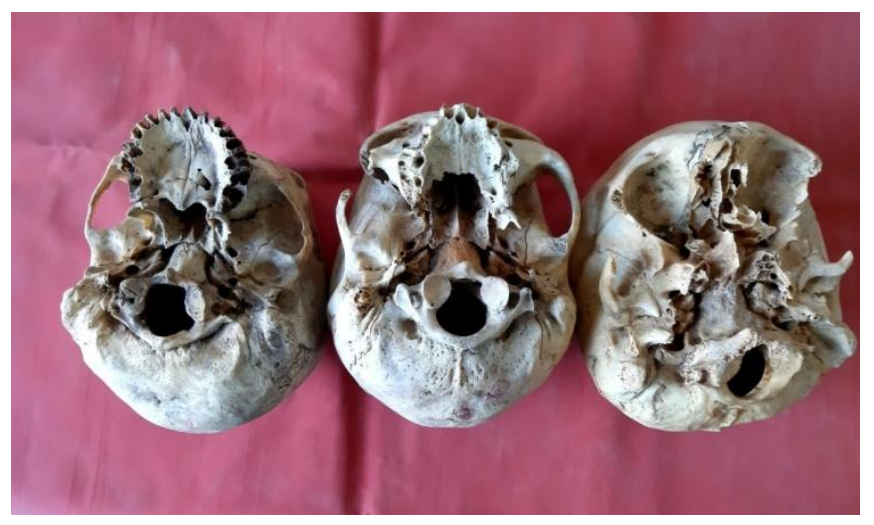

\section{Observation}

Three skulls out of the 350 dry skulls examined showed partial occipitalisation of the atlas.

Skull - 1

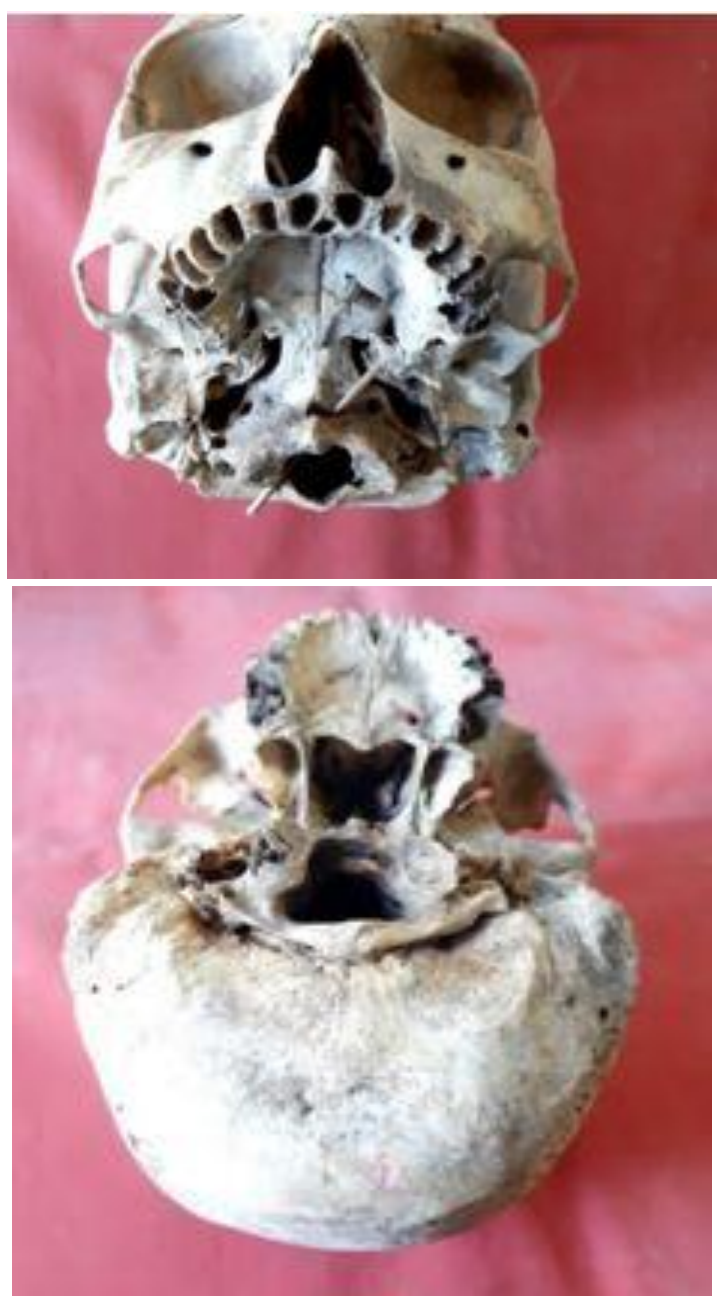


The superior articular facets and the transverse process were found to be fused with the occipital condyles. The anterior arch was also found to be fused with the occipital bone, however there was a small gap between the anterior arch and the occipital bone on the left side giving an appearance of a irregular foramen. The posterior arch was fused with the occiput on the right side but there was a gap on the left side. The inferior articular facets were rough and oval in shape. The Right inferior articular facet was pushed into the foramen magnum, shape of the foramen magnum was asymmetrical.

Skull - 2

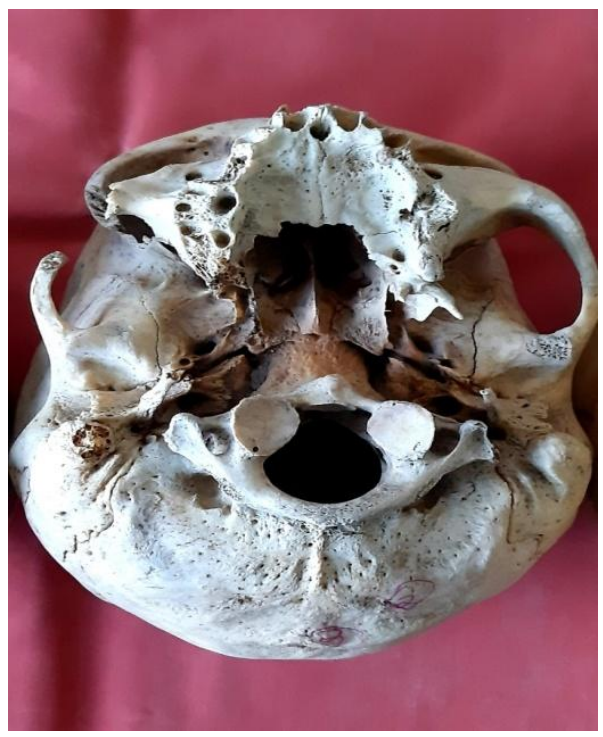

The superior articular facet was completely fused with the occipital condyles. The anterior arch along with the anterior tubercule was fused with the basiocciput however a small gap was present between the anterior arch and the basic occiput on both the sides resembling two foramen. The transverse process, its tip, the posterior arch and the posterior tubercule were not fused with the occipital bone.

The inferior articular facet was circular in shape and had a smooth surface. The fusion of the atlas to the occiput on the whole as a little to the left of the midline. The Right inferior articular facet was found projecting into the foramen magnum and hence its shape was asymmetrical.
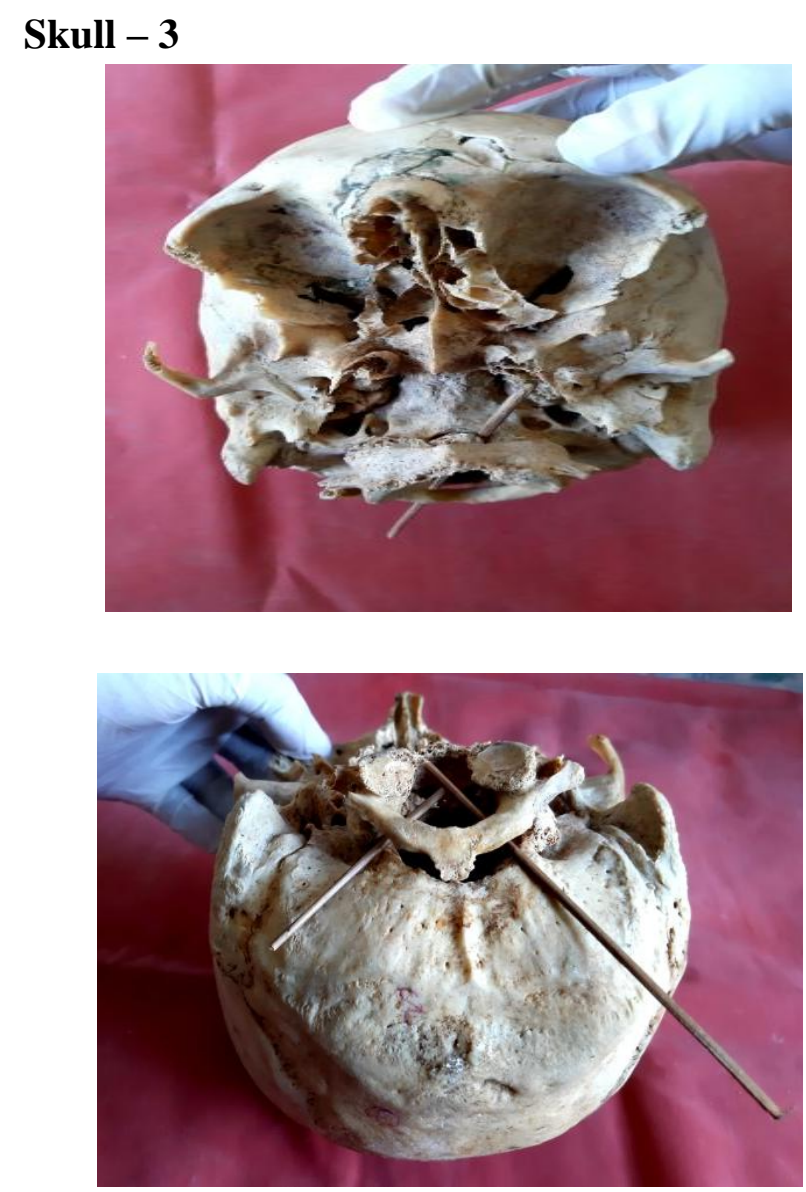

The superior articular facet was to the occipital condyles. The anterior tubercule and a part of the anterior arch was not fused with the basic occiput. The transverse process its tip posterior arch and the posterior tubercule were not fused with the occiput. The fusion was to the left of the midline. The inferior articular facets were circular in shape and its surface was rough. The foramen magnum was asymmetrical in shape and the fusion of the atlas was to the left of midline.

The hypoglossal canal foramen transversarium, anterior tubercules and posterior tubercules were identified in all the three bones and were found to be normal. The distance of the styloid process from the transverse process of atlas was found to be equal in all skulls. The mastoid process were prominent and normal in all the three skulls. No other cranio- facial anamolies were noted in the skull bones. 
Tabular Column 1:-

Foramen Magnum

\begin{tabular}{|l|c|c|c|}
\hline No: of Skull & $\begin{array}{c}\text { A.P Diameter of } \\
\text { Foramen Magnum }\end{array}$ & $\begin{array}{c}\text { Transverse Diameter of } \\
\text { Foramen Magnum }\end{array}$ & $\begin{array}{c}\text { Shape of Foramen } \\
\text { Magnum }\end{array}$ \\
\hline SKULL 1 & $29 \mathrm{~mm}$ & $30 \mathrm{~mm}$ & Asymmetrical \\
\hline SKULL 2 & $30 \mathrm{~mm}$ & $26 \mathrm{~mm}$ & Asymmetrical \\
\hline SKULL 3 & $30 \mathrm{~mm}$ & $25 \mathrm{~mm}$ & Asymmetrical \\
\hline
\end{tabular}

Tabular Column 2:-

Inferior Articular Facet

\begin{tabular}{|l|c|c|c|c|c|c|}
\hline \multirow{2}{*}{$\begin{array}{l}\text { No : of the } \\
\text { Skull }\end{array}$} & \multicolumn{2}{|c|}{ A.P } & \multicolumn{2}{c|}{ Transverse } & \multirow{2}{*}{ Surface } & \multirow{2}{*}{ Shape } \\
\cline { 2 - 5 } & R & L & R & L & & \\
\hline SKULL 1 & 1.9 & 1.9 & 1.2 & 1.2 & Rough & Elliptical \\
\hline SKULL 2 & 1.6 & 1.6 & 1.5 & 1.5 & Smooth & Round \\
\hline SKULL 3 & 2.0 & 2.0 & 1.5 & 1.5 & Rough & Round \\
\hline
\end{tabular}

\section{Embryology}

Occipital bone is formed partly from cartilage and partly from membrane ${ }^{[12]}$. The part of the bone lying above the superior nuchal line (ie) the inter parietal part of the occipital bone is membranous in ossification. The remaining part of the occipital bone is formed from cartilage. Fusion of the second. Third and fourth occipital Somite results in the formation of basic occiput except the occipital condyles ${ }^{[3]}$. Thus the occipital bone in formed from exoxcipital, supra occipital and basi occipital portions which are seen to surround the foramen magnum ${ }^{[8]}$.

The Sclerotome is the part of the somite. It surrounds the notochord and the neural tube, vertebra are formed by the fusion of the caudal part of a sclerotome with the cranial part of the sclerotome below. In lower forms of the vertebrates, the cranial part of the sclerotome below. In lower forms of the vertebrates, the cranial part of the first cervical sclerotome and the caudal part of the $4^{\text {th }}$ occipital sclerotome get fused and remains as a separate bone between the occiput and the c, cervical vertebra. This is called as 'Proatlas'. However in human this region gets fused with the occipital bone to form two structure namely, the occipital condyles and the tip of the dens $^{[3,8]}$.

The Caudal part of the $\mathrm{C} 1$ cervical sclerotome fuses with the cranial $1 / 2$ of $c 2$ cervical sclerotome and forms the lateral manes, the anterior arch and the posterior arch of atlas ${ }^{[4,13]}$.

This is followed by the process of resegmentation which results in the formation of atlas. Failure of the process of resegmentation results in occipitoatlantosynostosis, the degree varying according to the degree of failure of separation. This results in partial or complete synostosis.

Studies in lower animals for such cogenital malformation have been related to the varying degree of inactivation of gene expression, teratogens vrial infection due to cache valley virus arbovirus, pestivirus etc...

However in humans the role of hox 3 gene has been related to the occipito- cervical regional malformation $^{[13]}$.

\section{Results of Previous Studies, A Review of Literature}

\begin{tabular}{|l|c|c|c|c|c|}
\hline Author & $\begin{array}{c}\text { Year of } \\
\text { Study }\end{array}$ & $\begin{array}{c}\text { No/: of Skull } \\
\text { Examined }\end{array}$ & Race & $\begin{array}{c}\text { Race no/: of Skulls Showing } \\
\text { Occipitalisation of Atlas }\end{array}$ & $\begin{array}{c}\text { Incidenc } \\
\text { e }\end{array}$ \\
\hline Harrower & 1923 & 800 & Europe & 9 & $1.1 \%$ \\
\hline Tait 2 & 2000 & $\begin{array}{c}214 \text { white 103 } \\
\text { black }\end{array}$ & $\begin{array}{c}\text { South Africa } \\
\text { (white \& black) }\end{array}$ & 2 & $0.9 \%$ \\
\hline Masnicovaand Benus & 2003 & 74 & Europe & 1 & $1.4 \%$ \\
\hline Jayanthi V. kulkarni & 2003 & - & Indian & 2 & - \\
\hline $\begin{array}{l}\text { Al-Motabagani and } \\
\text { surendra }\end{array}$ & 2006 & 109 & Asian & 1 & $0.9 \%$ \\
\hline
\end{tabular}




\begin{tabular}{|l|c|c|c|c|c|}
\hline Ranade et al & 2007 & 98 & Indian & 2 & $1.6 \%$ \\
\hline Kassim et al & 2010 & 55 & Malaysian & 2 & $3.6 \%$ \\
\hline Jadhar et al & 2012 & 150 & Indian & 1 & $0.7 \%$ \\
\hline Mudhaliar et al & 2013 & 200 & Indian & 2 & $1 \%$ \\
\hline Radhikaparmesh et al & 2013 & 200 & Indian & 2 & $1 \%$ \\
\hline Dipti.A.Nimje et al & 2014 & 50 & Indian & 1 & - \\
\hline Hemamalini & 2014 & - & Indian & 1 & - \\
\hline Sweenwalia et al & 2014 & - & Indian & 3 & $2.3 \%$ \\
\hline $\begin{array}{l}\text { Konstantionosnat sis } \\
\text { et al }\end{array}$ & 2015 & 180 & European & 4 & $0.85 \%$ \\
\hline Present Study & 2017 & 350 & Indian & 3 & $2 \%$ \\
\hline
\end{tabular}

\section{A Review of Symptoms Reported by Various Authors in Cases of Occipitalisation of Atlas}

\begin{tabular}{|l|c|c|c|}
\hline S.No & Year & Author & Symptoms \\
\hline 1 & 1859 & Kussmal and Tenner & Convulsion reported in all the 3 cases seen. \\
\hline 2 & 1934 & Englander & Pain in the cervical region \\
\hline 3 & 1948 & Hadlay & Neurological symptoms \\
\hline 4 & 1961 & Eeller & $\begin{array}{c}\text { Pain in the cervicalic disorder. } \\
\text { additionally had tonicclonic convulsion. }\end{array}$ \\
\hline 5 & 1964 & Budin and sondheimer & $\begin{array}{c}\text { Pain in the cervical region during hypertension and cervical } \\
\text { pain while wearing sweaters. }\end{array}$ \\
\hline 6 & 1966 & Albert and castrischer & Pain is the cervical region \\
\hline 7 & 1968 & Childers and wilson & $\begin{array}{c}\text { Cervical pain in 25 reported cases. Asymplomatic in others } \\
\text { and some had insufficient data. }\end{array}$ \\
\hline 8 & 1971 & Vakili et al & Sudden death. \\
\hline 9 & 1985 & &
\end{tabular}

\section{Discussion}

The Atlanto occipital synostosis is categorized in to four major groups depending on the site of fusion of the occipital bone with the atlas. They are

Zone 1 - fusion involving the anterior arch in front of the lateral mass $(20 \%)$

Zone -2 Fusion involving primarily the lateral process $(17 \%)$

Zone -3 Fusion involving posterior arch of atlas behind the lateral mass $(13 \%)$

Combination of Zones - (50\%)

In the present study combination of zones was present in all the three bones.

The atlanto occipital fusion leads to compression of various structure like vertebral artery $\mathrm{C} 1$ cervical nerve posterior atlanto occipital membrane. Spinal cord all of which are related to the posterior arch of the atlas.

All the clinical symptomatology which sign from asymptomatic condition to sudden death and varied clinical presentations could be explained based on the compression of the above said structures.
The sagittal and transverse diameter of the foramen magnum are important in the synostosis. The normal sagittal diameter is $28-38 \mathrm{~mm}$ and the transverse diameter is $25-40 \mathrm{~mm}$.

Usually symptoms of spinal cord compression donot occur when the sagittal diameter of the foramen magnum is well above $18 \mathrm{~mm}$. Symptoms starts to appear when the diameter is around $15-17 \mathrm{~mm}$. Compresion of the spinal cord always occurs if the sagittal diameter behing the odontoid process is found to be equal or less than $14 \mathrm{~mm}$.

The condition is asymptomatic if the odontoid process doesnot project into the foramen magnum and is found well below the foramen magnum which could be assessed by of McRaes and Barnon line which passes across the foramen magnum. Clinical symptoms doesnot occur and the patient remains asymptomatic if the odontoid process is found below the line ${ }^{[8]}$.

As a result of the synostosis the first mobile segment to be encountered in the head and neck region shifts from occiput and $\mathrm{c} 1$ to $\mathrm{c} 1$ and $\mathrm{c} 2$ junctional region. This leads to restriction in the 
range of movements and stress in the area which causes the supporting myo ligamentous structures to undergo over stretching. This leads to a loose atlanto - axial joint. The condition is progressive and usually results in subluxation of atlanto axial joint. The clinical features of $c 2-c 3$ subluxation are torticollis which results in inclination of the head to a particular side, slight flexion and rotation of the neck to the contralateral side.

The clinical manifestations of the synostosis usually present in the second decade of the life even though the condition is congenital in occurrence the cause for the late presentation of the symptoms could be explained as follows, The tolerance of the central nervous system decreases with age due to frequent blows to the spinal cord from the odontoid process during flexion and extension movements of the neck

As a result the ligaments around the joint becomes lax and leads to instabilitity in the region which increases with age. This explains the progressive course of the condition which is the normal presentation although cases of sudden death have been reported.

Compression of the vertebral artery in the vertebral groove due to the lateral mass protruding in to the foramen magnum may produce symptoms which ranges from syncope dizziness vertigo tonic (or) clonic seizure to compromise in the blood flow to the brain.

Compression of the $\mathrm{C} 1$ cervical nerve may affect the action of the postural muscle like suboccipitalis which are present on the extension surface and can lead to an abnormal position of the head. The medulla may be compressed anteriorly producing symptoms and signs of dysfunction of long tract like hyper reflexia of upper and lower limbs, Hoffman's sign, spasticity, Babinski's sign. Compression of the posterior part of the cord produces signs and symptoms of posterior column involvements like numbness, paraesthesia, impairment of vibration, position sense and 2 point discrimination.
Involvement of the cranial nerves may produce visual and auditory disturbances and tinnitus. Involvement of lower cranial nerves produces dysarthria, dysphagia and nystagmus. The condition may be associated with other anomalies like

- $\mathrm{C} 2-\mathrm{C} 3$ fusion in (70\% of cases)

- Kyphosis and scoliosis

- Basilar invagination

- Urinary tract anomalies

- Incomplete cleft of nasal cartilage

- Cleft palate

- Spina bifida of atlas

- Klippel; feil syndrome

Patients have short neck, torticolis low hair line and restriction of neck movements The condition has to be distinguished from Arnold-chiarimal formation. Patients with minor symptoms are usually treated by conservative means like traction, immobilization in plaster or cervical orthrosis. Decompression (or) cervical spine fusion is indicated when neurological symptoms are present.

\section{Conclusion}

The Possibility of the condition should be kept in mind when treating a patient with pathologies of the upper cervical spine and neck pain. For a neuro surgeon the transverse process is an important landmark for locating various structures in the head and neck region, The synostosis may change the location of the various structures. Hence the knowledge of the condition is of at most importance.

\section{References}

1. Sween Walia, Bhawani Shankar Modi, Nidhi Puri, VV Gopichand Patnaik. Occipitalization of Atlas. Int $\mathbf{J}$ Anat Res 2014;2(4):781-784.

2. Yochum TR, Rowe LJ. Essentials of skeletal radiology. Volume 1, 2nd ed. Baltimore, William and Wilkins. 1987:p3. 
3. Nimje DA, Wankhede HA. Atlantooccipital fusion: A rare anomaly of the craniocervical junction. Edorium $\mathrm{J}$ Anat Embryo 2014;1:1-4.

4. Jayanthi V, Kulkarni R, Kulkarni RN. Atlantooccipital fusion-Report of two cases. Journal of the Anatomical Society of India 2003;52(1).

5. Mudaliar RP, Shetty S, Nanjundaiah K, Kumar J P, Kc J. An osteological study of occipitocervical synostosis: Its embryological and clinical significance. $\mathbf{J}$ Clin Diagn Res 2013 Sep;7(9):1835-7.

6. singhrajani, Is Variant Anatomy of Atlas Clinically Important A Review. Basic Sciences of Medicine 2014,3(1): 1-7

7. Sharma M, B. Singh, A. Abhaya1 and H. Kumar Occipitalization of atlas with other associated anomalies of skull Eur J Anat, 12 (3): 159-167 (2008).

8. Hussain Saheb et al, Occipitalization of Atlas:A Case Report.J Biomed Sci and Res;Vol 2(2),2010,73-7

9. Inderbir Singh,Text Book Of Human Osteology 2009;pg122

10. Grays Anatomy $40^{\text {th }}$ edition 2008;pg733.

11. T.S. Ranganathan Text Book Of Human Anatomy, $6^{\text {th }}$ edition pg617

12. Inderbir Singh, Human Embryology $9^{\text {th }}$ edition 2012;pg 130.

13. Carlson, Bruce M, Human Embryology And Developmental Biology, $4^{\text {th }}$ edition pg 140 . 